\title{
STUDY OF THE VARIANT ORIGIN OF LONG HEAD OF BICEPS BRACHII
}

\author{
Lakshmi Kiruba N ${ }^{1}$, Swapna B. Parate ${ }^{* 2}$, Prashant A. Bhusari ${ }^{3}$, Sonali Satpute ${ }^{4}$ \\ ${ }^{1}$ Assistant Professor, Dept. of Anatomy, SMBT IMS \&RC, Nashik, India. \\ ${ }^{* 2}$ Associate Professor, Dept. of Anatomy, SMBT IMS \&RC, Nashik, India. \\ ${ }^{3}$ Professor \& HOD, Dept. of Anatomy, SMBT IMS \&RC, Nashik, India. \\ ${ }^{4}$ Tutor, Dept. of Anatomy, SMBT IMS \&RC, Nashik, India.
}

\section{ABSTRACT}

Objectives: The objective of this study is to identify and categorize the variations in origin of tendon of long head of biceps brachii (LHBB).

Methods: The study was carried out on 60 upper limbs of cadaver in the Anatomy department, SMBT IMS \& RC, Nashik, India. After exposing the glenoid fossa, we find out the origin of tendon of LHBB from the supraglenoid tubercle and the adjoining glenoid labrum. Labrum is divided into anterior and posterior part.

Results: In 11 specimens origin of LHBB was seen from supraglenoid tubercle only, Other specimens has dual origin of LHBB along with Glenoid labrum. We classified it according to Vangsness et al. Type I: The labral attachment is entirely posterior, with no contribution to anterior labrum, seen in 31 specimens. Type II: The tendon attached mainly to the posterior part of the Glenoid labrum with also extended up to the anterior labrum, seen in 16 specimens. Type III: There are equal contribution to both the anterior and posterior parts of the labrum, found in only 2 specimens. Type IV: Most of the labral contribution is anterior, with a small contribution to the posterior labrum. No specimen found.

Conclusion: Anatomical variation in origin of LHBB help us to explain the correlation of recurrent shoulder dislocation and labral detachment.This knowledge is necessary to avoid errors in shoulder arthroscopy, radiological investigations and surgical repair.

KEY WORDS: Tendon of long head of Biceps Brachii (LHBB), Origin of long head of Biceps Brachii (LHBB), Stability of shoulder joint, Glenoid Labrum

Address for Correspondence: Dr. Swapna Parate, Associate Professor, Dept. of Anatomy, SMBT IMS \&RC, Nashik, India. Mobile No- 91-8600106094 E-Mail: drswapna.sorte@gmail.com

Access this Article online

Quick Response code

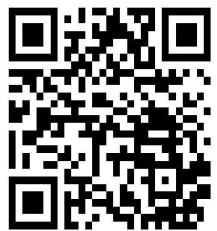

DOI: $10.16965 /$ ijar.2018.454
Journal Information

\section{International Journal of Anatomy and Research}

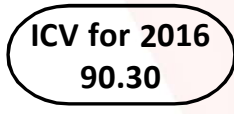

ISSN (E) 2321-4287 | ISSN (P) 2321-8967

https://www.ijmhr.org/ijar.htm

DOI-Prefix: https://dx.doi.org/10.16965/ijar

\section{Article Information}

Received: 26 Dec 2018

Peer Review: 27 Dec 2018

Revised: None
Accepted: 12 Feb 2019

Published (O): 05 Mar 2019

Published (P): 05 Mar 2019

\section{INTRODUCTION}

The biceps brachii is important muscle of anterior compartment of arm. It is powerful flexor of the elbow joint and supinator of the forearm. This muscle has two heads of origin, long head and short head. The long head provides stability to the shoulder joint by preventing upward dislocation. The long head of this muscle is considered to originate either from the supraglenoid tubercle of the scapula [1-5] or according to several studies have shown a dual attachment to the supraglenoid tubercle and adjoining part of the glenoid labrum of the scapula [6-9]. The aim of this study is to identify and categorize the variations in origin of tendon of long head of biceps brachii with the help of classification provided by Vangsness et al [10]. 
Understanding of variations in normal anatomy origin of tendon of long head of biceps brachii may help the surgeons to do arthroscopic diagnosis and surgical repair around shoulder joint incase of partial or complete detachment of the tendon from the labrum or both [11].

\section{MATERIALS AND METHODS}

The study was carried out on 60 upper limbs of cadaver in the Anatomy department, SMBT IMS $\&$ RC, Nashik, India after getting approval from institute ethical committee. To expose the glenoid fossa along with glenoid labrum and the long head of biceps brachii tendon (LHBB), all the muscles and blood vessels surrounding the gleno-humeral joint including joint capsules are incised. To find out the origin of tendon of long head of biceps brachii, the glenoid labrum is divided into anterior labrum and posterior labrum in order to identify and categorize the variations in attachment of tendon of LHBB to glenoid labrum.

Inclusion criteria: a) Right and left side scapula b) Scapula with clear and intact features c) Age above 25 years

Exclusion criteria: a) Broken and damaged scapula b) Scapula showing degenerative changes c) Age below 25 years

\section{OBSERVATIONS AND RESULT}

Total 60 scapulae were examined from both right as well as left side. The long head of biceps brachii tendon was seen to arise from supraglenoid tubercle only, total 11 specimen has such origin of LHBB (fig1). Other specimens has dual origin of LHBB along with Glenoid labrum, we found variations in its attachment along the labrum. Using the classification of Vangsness et al [10], the following types of tendon attachment were observed:

Type I: The labral attachment is entirely posterior, with no contribution to anterior labrum (Fig $2)$, seen in 31 specimens.

Type II: The tendon attached mainly to the posterior part of the Glenoid labrum with also extended up to the anterior labrum (Fig 3), seen in 16 specimens.

Type III: There are equal contribution to both the anterior and posterior parts of the labrum
(Fig 4), found in only 2 specimens.

Type IV: Most of the labral contribution is anterior, with a small contribution to the posterior labrum. No specimen found.

Table 1: Distribution of LHBB attachment.

\begin{tabular}{|c|c|c|c|c|}
\hline Location & Right & Left & Total & Percentage (\%) \\
\hline SupraGlenoid tubercle (ST) only & 7 & 4 & 11 & 18.3 \\
\hline ST and Glenoidal labrum (GL) & 24 & 25 & 49 & 81.7 \\
\hline
\end{tabular}

Fig. 1: The tendon arises only from Supra Glenoid tubercle.

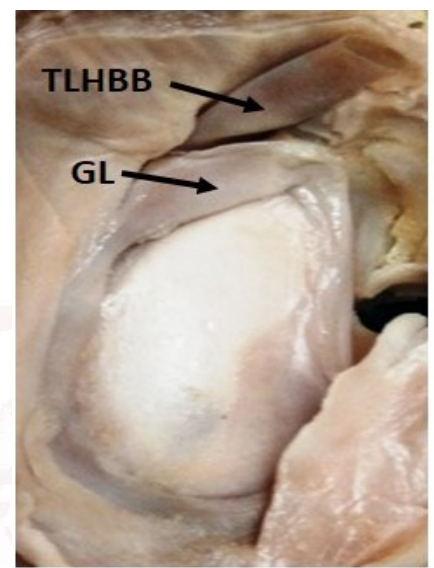

Table 2: Classification of dual origin of LHBB along with labrum.

\begin{tabular}{|c|c|c|c|c|}
\hline Type & Right & Left & Total & Percentage \\
\hline Type I & 13 & 18 & 31 & $51.70 \%$ \\
\hline Type II & 9 & 7 & 16 & $26.70 \%$ \\
\hline Type III & 2 & 0 & 2 & $3.30 \%$ \\
\hline Type IV & - & - & - & - \\
\hline
\end{tabular}

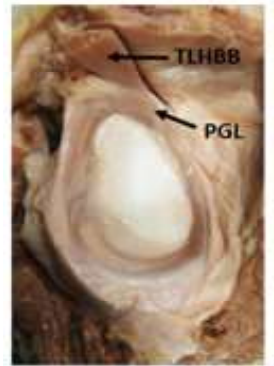

Fig 2: Type I

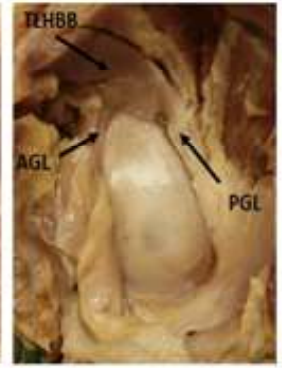

Fig. 3: Type II

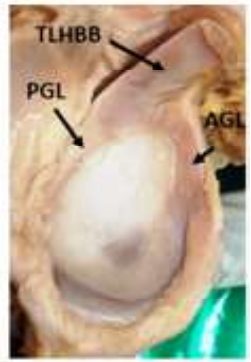

Fig. 4:Type III
TLHBB - Tendon of long head of biceps brachii, PGL - Posterior Glenoid labrum, AGL- Anterior Glenoid labrum.

\section{DISCUSSION}

The origin of long head of biceps brachii from the supraglenoid tubercle is described in standard textbook [1-6]. We found similar origin in $18.3 \%$ of specimens and Reis FP et al found it in 5\% specimens [12] and in 40-60\% according to Vangsness [10]. 
Our study has shown that $81.7 \%$ of specimens with dual origin of the LHBB, this finding is similar to the other authors [7-10] and less in number as compared to the finding of Reis FP et al., they found it in 95\% [12]. In the following table we compared our findings with other authors.

Table 3: Comparison of findings of our study with other Authors.

\begin{tabular}{|c|c|c|c|c|}
\hline Type & $\begin{array}{c}\text { Present } \\
\text { study(\%) }\end{array}$ & $\begin{array}{c}\text { Vangsness et al } \\
(\mathbf{1 9 9 4 )}[\text { [10] } \\
(\%)\end{array}$ & $\begin{array}{c}\text { KetanChauhan } \\
\text { et al (2013) [13] } \\
(\%)\end{array}$ & $\begin{array}{c}\text { AbduelmenemAlashkham } \\
\text { et al (2018) [14] } \\
(\%)\end{array}$ \\
\hline Type I & 51.7 & 22 & 74 & 47.7 \\
\hline Type II & 26.7 & 33 & 20 & 31.5 \\
\hline Type III & 3.3 & 37 & 6 & 16.2 \\
\hline Type IV & - & 8 & - & 4.6 \\
\hline
\end{tabular}

According to above table ketan Chauhan also did not find type IV attachment of LHBB that is similar to present study. Paul et al. agree that the long head consistently originated from the supraglenoid tubercle and glenoid labrum, with the tendon attached to the posterior and anterior parts of the glenoid labrum in $67 \%$ and $33 \%$ of specimens respectively [9].

Abduelmenem Alashkham et al found no significant difference in the type of tendon attachment and sex, side or age [14].

Boyd and Sisk [15] have made surgical use of this labral attachment in patients with detached posterior labrum by combining an operative posterior capsulorraphy with a transfer of tendon of long head around the neck of the humerus and across the posterior capsule to be reattached to the posterior scapular neck. The tendon may be elongated by as much as $1 \mathrm{~cm}$ to achieve this procedure due to the presence of its labral attachment.

Bankart described labral detachment in association with recurrent shoulder dislocation ${ }^{16}$. The term 'SLAP lesion' (superior labrumanterior to posterior) Synder et al. is used to describe and grade injuries in which all or part of the superior labrum is avulsed from the glenoid, along with the origin of the long head of the biceps [17].

Bey et al. demonstrated the importance of the posterior-superior region of the glenoid labrum in the transmission of forces through the LHBBT during effort and movement of the shoulder [18].

\section{CONCLUSION}

Anatomical variation in origin of long head of biceps brachii help us to explain the correlation of recurrent shoulder dislocation and labral detachment. As incomplete or wrong diagnosis can lead to treatment failure, it is important to recognize this entity which can help the surgeon in focusing the treatment on the actual pathology. Hence the knowledge of the normal variation in origin is necessary to avoid errors in shoulder arthroscopy, radiological investigations and surgical repair.

\section{Conflicts of Interests: None}

\section{REFERENCES}

[1]. Hollinshed WH. Anatomy for surgeons. Vol. 3 MoelerHarper, New York, 1958; 361.

[2]. Woodburne RT. Essentials of Human Anatomy $2^{\text {nd }} e d$. Oxford University Press, New York 1980; 87.

[3]. Hamilton WJ. Textbook of Human Anatomy $2^{\text {nd }} e d$ ELBS and Macmillan, London. 1978;169.

[4]. Snell RS. Clinical Anatomy for Medical Students $2^{\text {nd }}$ ed. Little Brown and Company, Boston. 1981;385.

[5]. Prodromos CC, Ferry JA, Schiller AL, Zarins B. Histological studies of the glenoid labrum from fetal life to old age. J Bone Joint Surg (AM). 1990;72-A:13448.

[6]. Gardner E, D.J. Gray, RO'Rahilly. Anatomy $4^{\text {th }}$ ed. W.B. Saunders, Philadelphia. 1975: 122.

[7]. Williams PL, Warwick R. Gray's anatomy. Thirtysixth ed. Edinburgh, etc: Churchill Livingstone, 1980.

[8]. Last RJ. Anatomy: Regional and Applied $7^{\text {th }}$ ed. Edinburg: Churchill Livingstone, 1984; 74.

[9]. Paul S, Sehgal R, Khatri K. Anatomical variations in the labral attachment of the long head of biceps brachii. J AnatSoc India, 2004;53(2):49-51.

[10]. Vangsness CT, Jorgenson SS, Watson T et al. The origin of the long head of the biceps from the scapula and glenoid labrum. An anatomical study of 100 shoulders. J Bone Joint Surg, 1994;76-B(6):951-954.

[11]. Vangsness CT. Jr Associate Professor, Chief of Sports Medicine, Department of Orthopaedics, 1510 San Pablo Street Suite 1994;322.

[12]. Reis FP, Aragao JA et al. Origin of the tendon of the long head of the biceps brachii muscle and its relationship with glenoid labrum in human fetuses. Int J. Morphol. 2009;27(1):169-172.

[13]. Ketan Chauhan, Meenakshi Bansal et al. Variations of origin of long head of biceps brachii muscle from glenoid labrum of scapula. National Journal of Medical Research. April- June 2013; 3(2):137-139.

[14]. AbduelmenemAlashkham et al. Origin of the long head of biceps brachii from the supraglenoid tubercle and glenoid labrum. Eur J Anat. 2018;22(3):213-219.

[15]. Boyd and Sisk, Recurrent posterior dislocation of the shoulder. J Bone Joint Surg. 1972; 779-86.

[16]. Bankart A. S. B. Pathology and treatment of recurrent dislocation of shoulder joint. Br. J. Surg, 1938;26:23-29. 
[17]. Snyder SJ, Karzel RP et al. SLAP Lesion of the shoulder arthroscopy 1990;6(4):274-9.

[18]. Bey MJ et al. The mechanism of creation of superior labrum, anterior and posterior lesions in a dynamic biomechanical model of the shoulder: the role of inferior subluxation. J Shoulder Elbow Surg, 1998;7:397-401.

How to cite this article:

Lakshmi Kiruba N, Swapna B. Parate, Prashant A. Bhusari, Sonali Satpute. STUDY OF THE VARIANT ORIGIN OF LONG HEAD OF BICEPS BRACHII. Int J Anat Res 2019;7(1.3):6265-6268. DOI: 10.16965/ijar.2018.454 